\title{
Effects of resistance training on liver structure and function of aged rats
}

Article in The Aging Male · July 2017

Dol: 10.1080/13685538.2017.1350157

CITATION

1

7 authors, including:

Ricardo Aparecido Baptista Nucci

University of São Paulo

8 PUBLICATIONS 9 CITATIONS

SEE PROFILE

Walter Krause Neto

Universidade São Judas Tadeu

28 PUBLICATIONS 72 CITATIONS

SEE PROFILE
Ana Caroline de Souza Teodoro

Universidade Federal de São Paulo

5 PUBlications 3 CITATIONS

SEE PROFILE

Wellington de Assis Silva

Universidade São Judas Tadeu

7 PUBlications 11 CitATIONS

SEE PROFILE

Some of the authors of this publication are also working on these related projects:

"Efeitos do treinamento físico aeróbio no pâncreas dislipidêmico ovariectomizadas." View project

body image disturbance in eating disorders View project 


\section{Effects of resistance training on liver structure and function of aged rats}

Ricardo Aparecido Baptista Nucci, Ana Caroline de Souza Teodoro, Walter Krause Neto, Wellington de Assis Silva, Romeu Rodrigues de Souza, Carlos Alberto Anaruma \& Eliane Florencio Gama

To cite this article: Ricardo Aparecido Baptista Nucci , Ana Caroline de Souza Teodoro, Walter Krause Neto , Wellington de Assis Silva, Romeu Rodrigues de Souza, Carlos Alberto Anaruma \& Eliane Florencio Gama (2017): Effects of resistance training on liver structure and function of aged rats, The Aging Male, DOI: 10.1080/13685538.2017.1350157

To link to this article: http://dx.doi.org/10.1080/13685538.2017.1350157

$$
\text { 巴nublished online: } 11 \text { Jul } 2017 .
$$

Submit your article to this journal $₫$

Q View related articles $\square$

View Crossmark data ¿ 


\title{
Effects of resistance training on liver structure and function of aged rats
}

\author{
Ricardo Aparecido Baptista Nucci ${ }^{\mathrm{a}} \mathbb{D}^{(D}$, Ana Caroline de Souza Teodoro ${ }^{\mathrm{a}}$ (D), Walter Krause Neto ${ }^{\mathrm{b}}$ (D), \\ Wellington de Assis Silva ${ }^{b}$ (D) Romeu Rodrigues de Souza ${ }^{a, b}\left(\mathbb{D}\right.$, Carlos Alberto Anaruma ${ }^{c}$ and \\ Eliane Florencio Gama ${ }^{\mathrm{a}, \mathrm{b}}$

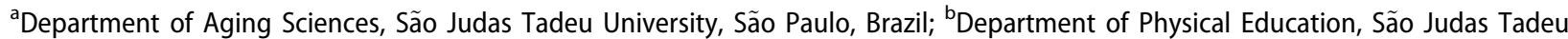 \\ University, São Paulo, Brazil; 'Department of Physical Education, "Julio de Mesquita Filho" São Paulo State University, São Paulo, \\ Brazil
}

\section{ABSTRACT}

The aging process may cause negative physiological changes. However, exercises as resistance training (RT) have been considered an important intervention to attenuate these changes. Additionally, liver plays an important role in blood glucose homeostasis in exercise.

Aim: This study aimed to analyze the effects of RT on the liver components of aged animals.

Methods: Male Wistar rats were divided into two groups: 24 months' group (CONTROL); and group submitted to a progressive RT protocol for 16 weeks (EXERCISE). Both groups were sacrificed at 24 months.

Results: We observed a decrease in blood flow due to the practice of resistance exercises. Besides, our results showed that hepatic tissue plays an important role in glycemic homeostasis during RT. In addition, RT increased mitogen capacity of hepatocytes.

Conclusions: Our study showed many implications for the knowledge about the effects of strength training on old animals' liver.

\section{ARTICLE HISTORY}

Received 21 June 2017

Revised 29 June 2017

Accepted 29 June 2017

Published online 10 July

2017

\section{KEYWORDS}

Liver; aging; resistance training; hepatic structure; exercise

\section{Introduction}

With increased longevity, the quality of life and general health of the older segments of society have become important topics of discussion and research [1].

The aging process may cause muscular weakness, increase the risk of falls and cognitive impairment in the elderly population [2-5]. However, older people who maintain a regular exercise routine have attenuated the physiological changes of the aging process [2-5].

Resistance training (RT) has been highlighted as an important factor for increasing strength and muscle mass in both young and older subjects $[2,6,7]$. Thus, the goal of achieving a RT program in the elderly is to maintain, and if possible, increase muscle and bone mass, thereby contributing to the maintenance of daily living activities $[2,8,9]$. Besides, in exercise, the hepatic tissue plays an important role in blood glucose homeostasis by glycogenolysis and gluconeogenesis [10].

Although many physiological effects of regular physical activity have been described in the literature [2-9], there is still unclear evidences about the effects of RT on hepatic structure and function in the elderly.

\section{Methods}

All experimental procedures conformed to the guiding principles of the American Physiology Society and were approved by the Ethical Committee of São Judas Tadeu University under the protocol number 001/ 2013.

To carry out this study, 12 male Wistar rats were used. The rats were randomly divided into two groups: (A) sedentary rats with 24 months of age (CONTROL, $n=6$ ); (B) rats with 20 months that were subjected to RT for 16 weeks, totaling 24 months of age (EXERCISE, $n=6$ ). The body weight (BW) was measured at the beginning of each week.

All animals in the RT group underwent a preadaptation to the training protocol and equipment for three days. The equipment used to carry out the strength training program with the animals was a vertical ladder made of wood with iron steps. The height of the equipment (ladder) is $110 \mathrm{~cm}(43.3$ inches) with an inclination angle of $80^{\circ}$. The top of the equipment had a plastic box for the accommodation of the animals in the interval between sets $[11,12]$.

CONTACT Ricardo Aparecido Baptista Nucci r.aparecido.nucci@uol.com.br Đ Department of Aging Sciences, São Judas Tadeu University, 546, Taquari st., São Paulo, Brazil

(C) 2017 Informa UK Limited, trading as Taylor \& Francis Group 
The training protocol was progressive with the load being adjusted every week. The load was composed of lead weights that were attached to their tails with a velcro tape. The animals were supposed to climb the ladder to reach the resting area at the top that was considered one repetition. The adaptation process was three days with four repetitions every day.

The rats in exercise group were trained once a day throughout three days per week for 16 weeks with a rest interval of $60 \mathrm{~s}$ between repetitions. Each training session consisted of six to eight climbs. Over the course of 16 weeks, the amount of weight carried by each rat was equivalent to $50 \%$ of its body weight (BW). The BW was measured at the beginning of each week of the experiment and the new weight to be carried by the animals during that week was adjusted according to their BW [11,12]. No external stimulus was necessary so that the animals conduct the training.

After the experiments, the animals were sacrificed by $\mathrm{CO}_{2}$ method and the liver was removed. Then fragments of liver were fixed in $10 \%$ buffered formalin and dehydrated in an increasing series of alcohols. They were cleared in xylene, embedded in paraffin, sectioned in $5 \mu \mathrm{m}$ thick sections and stained with hematoxylin and eosin (HE) and periodic acid of Schiff (PAS) for light microscopy analysis.

The histological sections stained with HE were used to analyze the area and the numerical density of hepatocytes and other liver cells using the Axio Vision software (version 4.9.1). For numerical density, we counted all the cells (hepatocytes or other liver cells, e.g. Kupffer and Stellate cells without discrimination) in each field [13].

In HE histological sections we analyzed, through stereological methods, the volume density of lobular parenchyma components (capillaries sinusoids, peri sinusoidal spaces and biliary ducts) and non-lobular parenchyma components (portal spaces, veins and center-lobular branches of blood vessels). Finally, the sections stained with PAS were used to analyze the percentage of glycogen present in the tissue [13]. For the determination of numerical density of glycogen, Image J software (National Institute of Health, version $1.45 \mathrm{~s}$ ) was used. It was done by counting the number of structures present in the photographic field of microscopic field. The structure which touched the lines to the right and upwards on the screen were disregarded, while those which that touched the lines on the left and downward were considered [14].

Statistical analyzes were performed using GraphPad Prism 5.0 software (GraphPad Prism, Inc., San Diego,
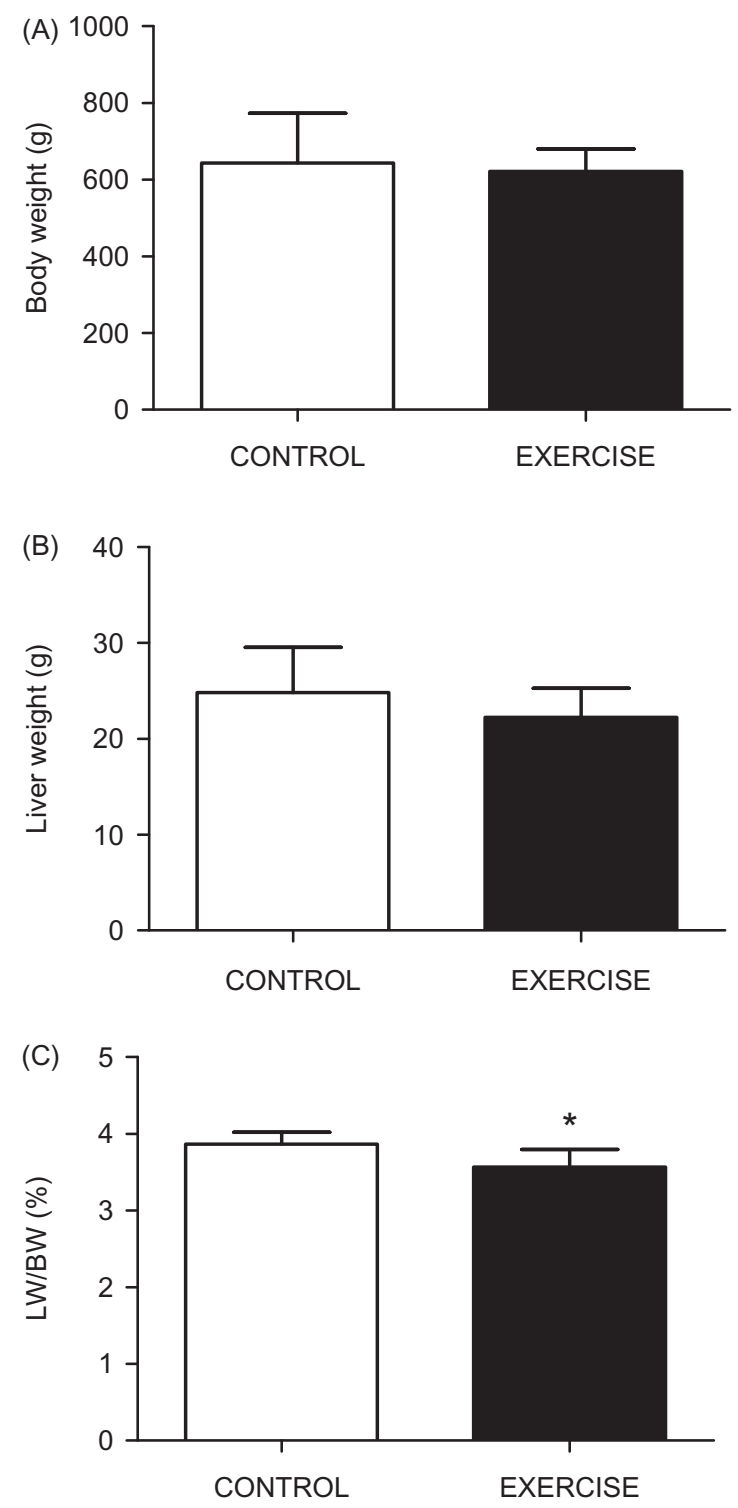

Figure 1. (A) body weight (BW g). (B) Liver weight (LW g). (C) Relative liver weight times 100 (LW/BW \%). Data shown as mean \pm SD. $* p<0.05$.

CA, USA). Student's $t$-test was used to compare groups and summary data reported as mean values \pm standard deviation. A $p<0.05$ was considered statistically significant.

\section{Results}

No significant difference was observed between groups for body weight and liver weight (Figure 1). However, relative liver weight times 100 (LW/BW \%) decreased with exercise $(p<0.05)$.

Figure 2 shows a sharp decrease in both lobular parenchyma components (LPC \%) and non-lobular parenchyma components (NLP \%) in the group submitted to RT $(p<0.05)$. Furthermore, we highlight in our 

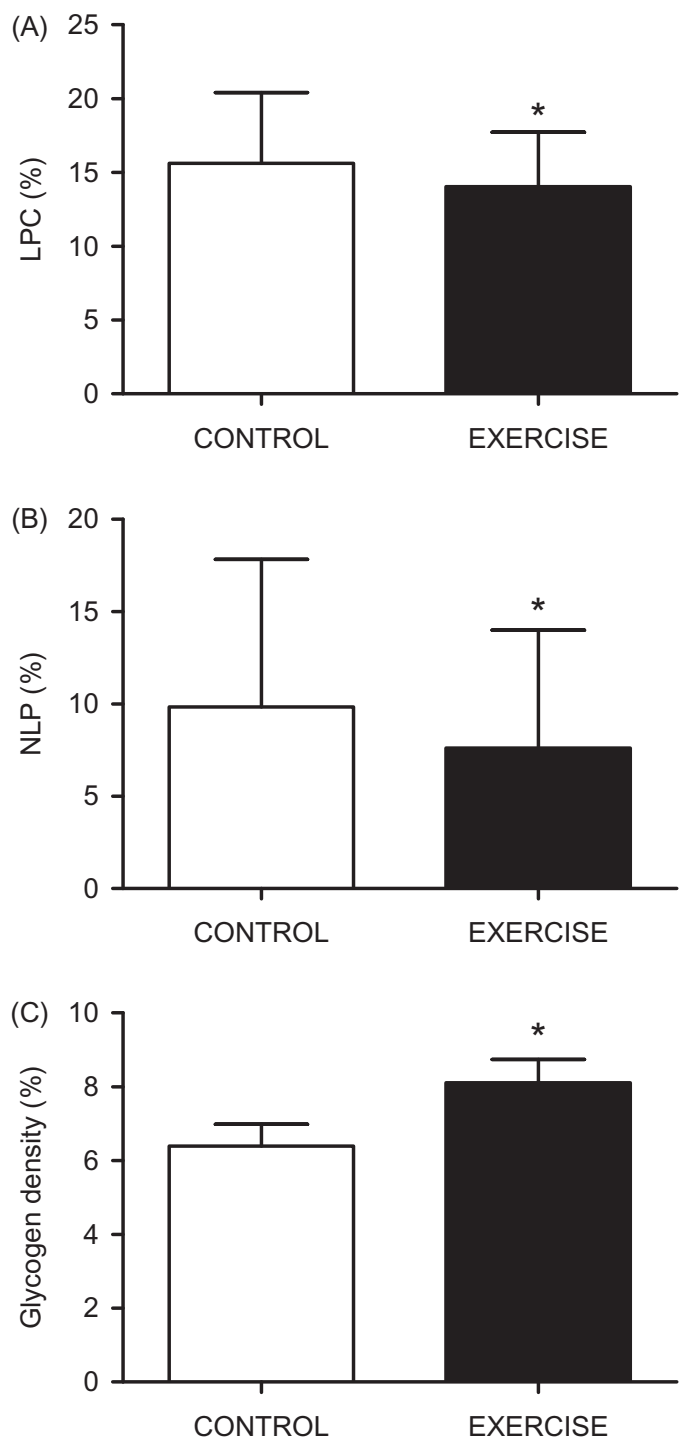

Figure 2. (A) lobular parenchyma components (LPC \%). (B) Non-lobular parenchyma components (NLP \%). (C) Glycogen density (\%). Data shown as mean \pm SD. ${ }^{*} p<0.05$.

study a sharp increase in hepatic glycogen in the exercise group $(p<0.05)$.

Figure 3 shows a subtle, but statistically significant, increase in hepatocytes area $\left(\mu \mathrm{m}^{2}\right)$ with strength training, in which exercise has increased hepatocytes area in $1.18 \%(p<0.05)$. In addition, we observed an increase in number of nuclei of hepatocytes (NNH) per field with RT $(p<0.05)$. The results indicate an $13.87 \%$ increase of NNH per field with RT. However, other liver cells (OLC) per field, had no significant difference between groups.

\section{Discussion}

Our study analyzed the effects of RT on the liver components of old animals. Observing Figure 1, we can see that strength training did not changed
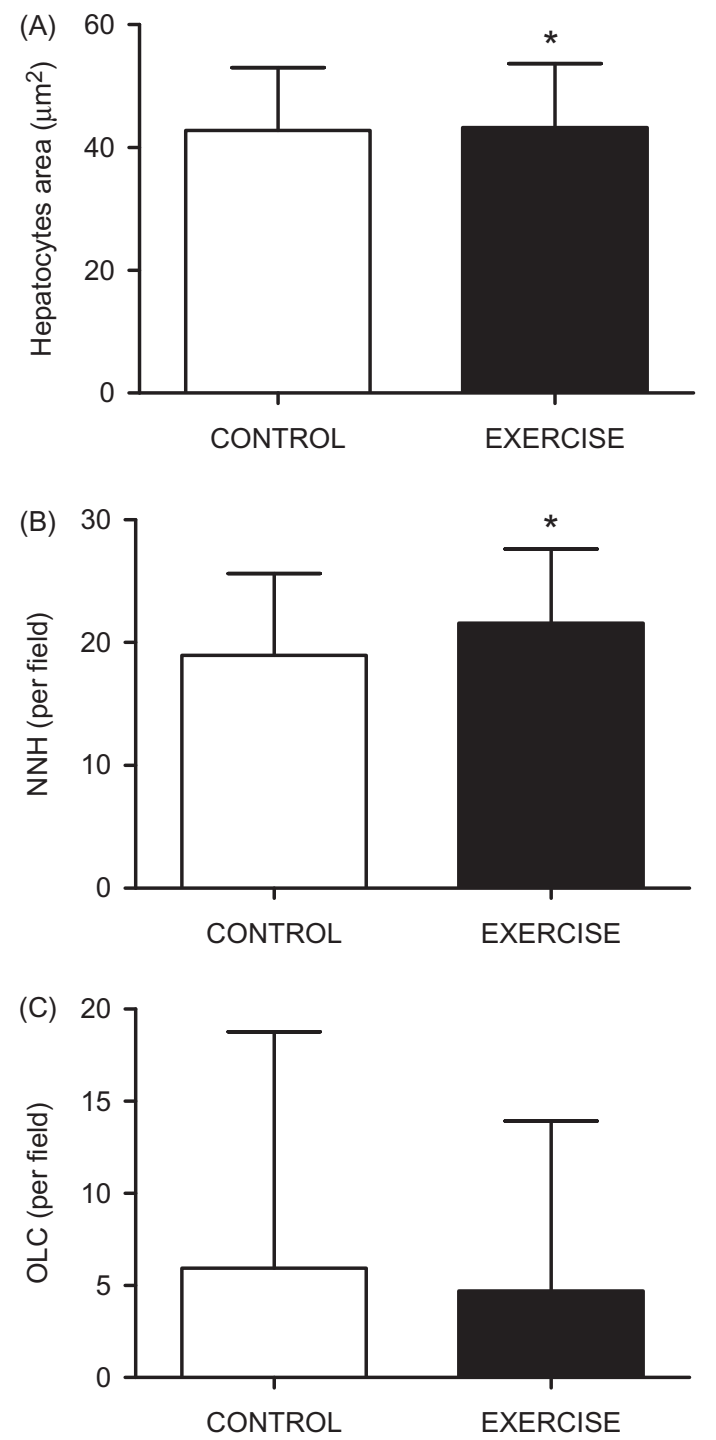

Figure 3. (A) Area of hepatocytes $\left(\mu \mathrm{m}^{2}\right)$. (B) Numerical density of hepatocytes (NNH) per field. (C) Other liver cells (OLC) per field. Data shown as mean \pm SD. ${ }^{*} p<0.05$.

body weight. In our experimental model, we did not used a high-intensity RT, which could explain the body weight maintained in the exercise group [15].

We can see that the absolute weight of the liver did not change with RT. In order to have no doubts about these results, we performed the relative liver weight, established by the ratio of the total liver weight (absolute weight) divided by the final BW of the animal times 100 . Regarding to the relative liver weight (Figure $1(C)$ ), we observed that RT is a factor that decreases liver mass. Additionally, in Figure 2, we suggest, using LPC \% and NLP \%, that RT may reduce blood flow in the liver. According to van Wijck et al. [16] these results may be related to splanchnic hypoperfusion. Drainage of the splanchnic area is covered by the superior mesenteric vein, inferior mesenteric vein, and the portal vein, which return the venous 
blood to the heart via the liver and subsequently the inferior vena cava $[16,17]$. The splanchnic vasculature promotes vasodilatation or constriction via regulation of the mesenteric vascular resistance by neuroendocrine, humoral, and paracrine mechanisms $[16,18]$. During exercise, the release of norepinephrine near the $\alpha$-adrenoreceptors of the sympathetic nervous system induces splanchnic vasoconstriction, thereby increasing total splanchnic vascular resistance $[16,17,19,20]$. The blood is rapidly redistributed from the splanchnic area to be used for the perfusion of tissues with increased activity during exercise, such as heart, lungs, active muscle, and skin $[16,21,22]$.

Moreover, exercise is a condition that results in fast mobilization and redistribution of substrates for the performance of muscle activity, which numerous changes in hormone secretion and metabolism become necessary for the maintenance of homeostasis [23]. In the exercise, the hepatic tissue plays an important role in maintaining blood glucose [10]. Our result, furthermore, provides evidence that hepatic glycogen stores undergoes adaptations to resistance exercise, as the trained group had more glycogen reserves than the sedentary group.

After a finite number of divisions, primary cell cultures enter a state of replicative senescence in which oxidants and antioxidants plays an important role in cellular signaling to further mitogenic stimulation [24]. If oxidative stress and the ability to respond appropriately to it is important in ageing, then it follows that factors that increase resistance to stress should have anti-ageing benefits and lead to enhanced life span [24,25].

Exercise increases oxygen consumption and reactive oxygen species (ROS) generation and, therefore, can enhance oxidative damage to nucleic acids in cells [25-28]. On the other hand, it has been well recognized that regular physical activity has health benefits such as reducing risk and progression of cardiovascular diseases, type 2 diabetes mellitus, cancer and neurodegenerative diseases [25,29-31]. Paradoxically, these diseases are suggested to be induced and exacerbated by ROS [25]. Additionally, Oliveira et al. [32] showed that animals submitted to aerobic exercise had the lower percentage of polyploids nuclei. Polyploidy results from incomplete mitotic cycles, which is tightly related to the aging process [32-34]. Our results in Figure 3 showed that the number of hepatocytes nuclei per field (NNH per field) were higher in animals submitted to RT, suggesting that exercise increase hepatocytes mitotic cycles increasing its numerical density and maintaining its area across age.
These results may be related to the protective effect of regular exercise even on hepatic cells.

In conclusion, there are three major findings in the present study. First, a decrease in blood flow due to the practice of resistance exercises suggesting a splanchnic hypoperfusion. Second, our results provide evidence that hepatic glycogen stores undergo adaptations to resistance exercise, demonstrating that liver plays an important role in glycemic homeostasis during RT. Finally, a numerical increase in hepatocytes with RT due to a potential antioxidant effect of regular exercise on liver cells.

\section{Acknowledgements}

The authors wish to thank Dr. Carlos Alberto Anaruma, José Roberto Rodrigues da Silva and Eduardo Custódio, "Julio de Mesquita Filho" São Paulo State University, São Paulo, Brazil, and Magna Soares, Butantan Institute, São Paulo, Brazil, for technical support.

\section{Disclosure statement}

The authors report no declaration of interest.

\section{ORCID}

Ricardo Aparecido Baptista Nucci (D) http://orcid.org/00000001-5649-2145

Ana Caroline de Souza Teodoro (ID http://orcid.org/00000002-8507-2964

Walter Krause Neto iD http://orcid.org/0000-0002-6881-0208

Wellington de Assis Silva (iD) http://orcid.org/0000-0001-63435501

Romeu Rodrigues de Souza iD http://orcid.org/0000-00023251-276X

Eliane Florencio Gama (D) http://orcid.org/0000-0002-97708819

\section{References}

[1] Kawasaki T, Sullivan CV, Ozoe N, et al. A long-term, comprehensive exercise program that incorporates a variety of physical activities improved the blood pressure, lipid and glucose metabolism, arterial stiffness, and balance of middle-aged and elderly Japanese. Hypertens Res. 2011;34:1059-1066.

[2] Peterson MD, Rhea MR, Sen A, et al. Resistance exercise for muscular strength in older adults: a meta-analysis. Ageing Res Rev. 2010;9:226-237.

[3] Province MA, Hadley EC, Hornbrook MC, et al. The effects of exercise on falls in elderlypatients. A preplanned meta-analysis of the FICSIT Trials. Frailty and Injuries: Cooperative Studies of Intervention Techniques. JAMA. 1995;273:1341-1347.

[4] Chang JT, Morton SC, Rubenstein LZ, et al. Interventions for the prevention of falls in older 
adults: systematic review and meta-analysis of randomised clinical trials. BMJ. 2004;328:680.

[5] Heyn P, Abreu BC, Ottenbacher KJ. The effects of exercise training on elderly persons with cognitive impairment and dementia: a meta-analysis. Arch Phys Med Rehabil. 2004;85:1694-1704.

[6] Mayhew DL, Kim JS, Cross JM, et al. Translational signaling responses preceding resistance training-mediated myofiber hypertrophy in young and old humans. J Appl Physiol. 2009;107:1655-1662.

[7] Raue U, Slivka D, Minchev K, et al. Improvements in whole muscle and myocellular function are limited with high-intensity resistance training in octogenarian women. J Appl Physiol. 2009;106:1611-1617.

[8] Hurley BF, Hagberg JM3. Optimizing health in older persons: aerobic or strength training? Exerc Sport Sci Rev. 1998;26:61-90.

[9] Evans WJ. Exercise training guidelines for the elderly. Med Sci Sports Exerc. 1999;31:12-17.

[10] Cunha TS, Tanno AP, Moura MJCS, et al. Influence of high-intensity exercise training and anabolic androgenic steroid treatment on rat tissue glycogen content. Life Sci. 2005;77:1030-1043.

[11] Hornberger TA, Jr Farrar RP. Physiological hypertrophy of the FHL muscle following 8 weeks of progressive resistance exercise in the rat. Can J Appl Physiol. 2004;29:16-31.

[12] Gonçalves L, de Souza RR, Maifrino LBM, et al. Resistance exercise and testosterone treatment alters the proportion of numerical density of capillaries of the left ventricle of aging Wistar rats. Aging Male. 2014;17:243-247.

[13] Nucci RAB, Teodoro ACS, Krause Neto W, et al. Effects of testosterone administration on liver structure and function in aging rats. Aging Male. 2017;20:134-137.

[14] Mandarim-de-Lacerda CA. Stereological tools in biomedical research. An Acad Bras Cienc. 2003;75: 469-486.

[15] Campbell WW, Crim MC, Young VR, et al. Increased energy requirements and changes in body composition with resistance training in older adults. Am J Clin Nutr. 1994;60:167-175.

[16] van Wijck K, Lenaerts K, Grootjans J, et al. Physiology and pathophysiology of splanchnic hypoperfusion and intestinal injury during exercise: strategies for evaluation and prevention. Am J Physiol. Gastrointest Liver Physiol. 2012;303:G155-G168.

[17] Mensink PB, Moons LM, Kuipers EJ. Chronic gastrointestinal ischaemia: shifting paradigms. Gut. 2010;60:722-737.

[18] Matheson PJ, Wilson MA, Garrison RN. Regulation of intestinal blood flow. J Surg Res. 2000;93:182-196.
[19] Gil SM, Yazaki E, Evans DF. Aetiology of runningrelated gastrointestinal dysfunction. Sports Med. 1998;26:365-378.

[20] Wright $H$, Collins M, De Villiers R, et al. Are splanchnic hemodynamics related to the development of gastrointestinal symptoms in ironman triathletes? A prospective cohort study. Clin J Sport Med. 2011;21:337-343.

[21] Otte JA, Oostveen E, Geelkerken RH, et al. Exercise induces gastric ischemia in healthy volunteers: a tonometry study. J Appl Physiol. 2001;91:866-871.

[22] Qamar MI, Read AE. Effects of exercise on mesenteric blood flow in man. Gut. 1987;28:583-587.

[23] Marliss EB, Kreisman SH, Manzon A, et al. Gender differences in glucoregulatory responses to intense exercise. J Appl Physiol. 2000;88:457-466.

[24] Finkel T, Holbrook NJ. Oxidants, oxidative stress and the biology of ageing. Nature. 2000;408:239-247.

[25] Nakamoto H, Kaneko T, Tahara S, et al. Regular exercise reduces 8-oxodG in the nuclear and mitochondrial DNA and modulates the DNA repair activity in the liver of old rats. Exp Gerontol. 2007;42:287-295.

[26] Davies KJ. Intracellular proteolytic systems may function as secondary antioxidant defenses: an hypothesis. J Free Radic Biol Med. 1986;2:155-173.

[27] Lovlin R, Cottle W, Pyke I, et al. Are indices of free radical damage related to exercise intensity. Eur J Appl Physiol Occup Physiol. 1987;56:313-316.

[28] Poulsen HE, Loft S, Vistisen K. Extreme exercise and oxidative DNA modification. J Sports Sci. 1996; 14:343-346.

[29] Larson EB, Wang L, Bowen JD, et al. Exercise is associated with reduced risk for incident dementia among persons 65 years of age and older. Ann Intern Med. 2006;144:73-81.

[30] Shephard RJ, Futcher R. Physical activity and cancer: how may protection be maximized? Crit Rev Oncog. 1997;8:219-272.

[31] Singh MAF. Exercise comes of age rationale and recommendations for a geriatric exercise prescription. J Gerontol Ser A: Biol Sci Med Sci. 2002;57: M262-M282.

[32] Oliveira HC, Paoli FD, Campos Vidal BD, et al. Hepatocyte nuclear phenotype, the cross-talk between anabolic androgenic steroids and exercise in transgenic mice. Histol Histopathol. 2008;23: 1367-1377.

[33] Schmucker DL. Age-related changes in liver structure and function: implications for disease? Exp Gerontol. 2005;40:650-659.

[34] Nucci RAB, Teodoro ACS, Gama EF. Liver regeneration and aging: a review. J Morphol Sci. 2016;33:179-182. 